\title{
Utilizing Flipped Learning in the English Language Classroom: A Study on a Movie, Love Actually-Based Curriculum
}

\begin{abstract}
Lim, Juyoung
(Jungwon University)

Lim, Juyoung. (2018). Utilizing flipped learning in the English language classroom: A study on a movie, Love actually-based curriculum. STEM Journal, 19(4), 91-108.

The purpose of this study is to understand the effects of a movie-based curriculum in a flipped learning environment, using a movie, Love Actually (Curtis, 2003) on undergraduate English learners via 1) analysis on the advantages and weaknesses of flipped learning, 2) analysis on student opinions concerning plot presentation, and 3) investigation of student opinions on class discussion as a preliminary learning tool. To accomplish this purpose, this study conducted a questionnaire-based survey on 42 undergraduate students for 15 weeks. To investigate the general characteristics of the research subjects, this study carried out frequency analysis. Also, to verify the mean differences in accordance to such general characteristics, this study conducted a t-test. Also, along with categorical data and $\mathrm{Z}$ values of individual departments, nonparametric test was utilized to investigate differences between each group. The results are as follows: 1) the greatest merit of the movie-based English class utilizing flipped learning was motivating students for learning, 2) the greatest weakness of it was that it was difficult to expect improved vocabulary and grammar skills, 3) students had positive opinions about the plot presentation and 4) class discussion, and 5) gender had lower influence on students' opinion of the merits and weaknesses of the class.
\end{abstract}

\section{INTRODUCTION}

The fourth Industrial Revolution, which involves the convergence of AI, the Internet, and ICT is characterized by an ultra-connected society. This implies that there will be dramatic changes to the whole social system - not only economic, political or cultural systems - caused by unprecedentedly fast, broad and deep impacts. The digital native generation surrounded by digital devices does not feel the value of physical content, such as libraries used by students in the past. Now that it has become routine for this new generation to utilize digital information, such as content and resources through Google, a 
new learning method is demanded to replace the traditional, obsolete educational methods of the past, which utilize materials like physical textbooks.

With an increasing number of digital devices widely-spreading, there have been a rising number of cases where such devices are being used for individual learning at home. The boundary between home learning and class learning is blurring. Recently, the American textbook market, which once reached annual sales of 8 billion dollars, has been threatened and challenged by digitalization. The suppliers of educational contents are digitalizing existing textbooks and are focusing on the development of online 1-to-1 learning programs. The scale of the global educational hardware market as of last year was 11.6 billion dollars, of which mobile PCs and classroom displays accounted for 59\% and 36\%, respectively. Such a change in education based on the utilization of wired and wireless information and communication devices has also been rising gradually in universities. Coursera, an online program established by Stanford University officials, has been offered at 62 universities, and more than 2.8 million students are enrolled in the program.

However, there are diverse opinions and results regarding the educational effectiveness of such digital textbooks when they are substantially utilized in class. As for the satisfaction of utilizing digital textbooks, Son and Kim (2013) presented suggestive points and potentials for the effective utilization of digital textbooks, emphasizing the proven positive effectiveness of digital textbooks in problem solving ability and learning satisfaction for social studies. Meanwhile, Park (2008) stated that while tablet PCs were utilized in elementary English education they were not adequate to be used for various activities during class. Lim (2010) claimed that without proper consideration of a wide range of classroom situations in school, the utilization of digital textbooks could hardly improve educational effectiveness or draw attention as an innovative educational element, mentioning the merits and weaknesses of a digital textbook-oriented class.

Therefore, improvements in current English education in universities would have to be made in the direction of enhancing basic educational competences and creative convergence/integration ability while also reflecting current tastes and epochal changes. Flipped learning could provide a novel solution to this problem as an educational method connecting the past with the future, since such learning allows for a student-centered class, in this case utilizing digital devices to watch a movie anytime and anywhere. Undergraduate students taking a movie-based class utilizing flipped learning are to take part in preliminary learning by watching a movie, and then summarizing the plot and preparing discussion questions in groups. Then, their plot summaries and questions are revised according to feedback from the instructor and used in the classroom for presentation and discussion. In this way, students are expected to participate in class as active subjects of learning rather than passive spectators as in a traditional instructorcentered classroom. The research questions of this study according to the research aim are 
as follows:

1. What are the merits of a movie-based English class utilizing flipped learning?

2. What are the weaknesses of a movie-based English class utilizing flipped learning?

3. What are student opinions about presenting plot summaries as part of preliminary learning in a movie-based English class utilizing flipped learning?

4. What are student opinions about having discussions as part of class activity in a movie-based English class utilizing flipped learning?

5. What are the opinions according to gender, about the merits and weaknesses of a movie-based English class utilizing flipped learning?

\section{LITERATURE REVIEW}

\section{Interaction}

In the 1980s, Krashen (1982) used the term 'input' for the first time in the field of foreign language education. Especially, he claimed that an instructor must utilize a wide range of realia or authentic materials to provide comprehensible input. Thus, Krashen's input theory implies an association between better second language education and comprehensible input. Schmidt (1990) stated that only a limited amount of input is retained as a learning effectiveness, calling such retained input 'intake,' which would eventually be converted to intake.

It is true that because of the limited amount of time allowed in classrooms, English teachers have difficulties handling sufficient amounts of vocabulary, reading and listening in an interesting way with real-life applications. In contrast, movies can eliminate learners' fear associated with listening and speaking, and at the same time, motivate them to engage in English learning (Gardner, Lalonde, Moorcroft, \& Evers, 1987). Kimbell (2018) showed how a class utilizing a US TV drama with closed captioning could improve English vocabulary, listening and reading skills (Gardner et al., 1987).

For such a reason, movies have been widely used as a practical tool for foreign language learning in classrooms - as it enables the simultaneous learning of listening, speaking, reading, writing, and even pronunciation (Hayati \& Mohmedi, 2011; Lee \& Lee, 2012; Stempleski, 2000). In addition, it is more efficient to learn grammar or reading skills by watching a movie than by simply reading a textbook because unlike a book, a movie allows 
content-focused learning making it easier for students to remember the story. In support of this, Lewis (2000) stated that language is acquired based not on language grammar but examples that have already been stored in the brains of learners. Moreover, the utilization of movies in class enables students to learn cultural backgrounds and differences in a natural manner (Choe \& You, 2003). For this reason, movies have been frequently used as a tool for foreign language classes (Bueno, 2009; Roell, 2010).

The cognitive stage of foreign language learning is not simple but involves complex processes of seeing with the eyes, hearing with the ears, and reorganizing the things obtained with the eyes and ears into verbal structures and then integrating all the verbal structures into meaningful expressions. According to the cognitive theory of Mayer (2002), a learner chooses verbal and visual data from input and reorganizes the chosen data into visual and verbal expressions and then integrates the resulting expressions together. Learning a foreign language through a movie involves these three processes - that is, the closed captions and pictures on the screen can serve as the first input (Yoon \& Ahn, 2012); the script in English as the second input (Koh, 2013), and the script in the learners' native language as the last input (Pak, 2013). Galloway (1992) stated that a person who learns a foreign language through authentic material such as a movie goes through four stages: 1) thinking in the native language upon being stimulated by text written in the foreign language, 2) becoming convinced it through various assumptions and anticipations based on observations, 3) studying and verifying the culture of the foreign language, 4) integrating information or knowledge acquired through the existing knowledge or new data.

Another important factor in the process of foreign language learning would be motivation by fellow students studying together. Interaction between classmates makes them motivated to learn, reveals what they need to improve and develops their potential through mutual competition. Vygotsky (1978) stated that there was a distance between the level of actual development and the level of potential development that could be reach by solving problems with help or co-operation from competent colleagues-calling the distance the "the zone of proximal development" (p. 86). Also, he added that interaction between colleagues is an important part of the learning process, and that it is necessary for students of lower competency to be partnered with students of higher competency, while learning a new skill. In this sense, group activities during a learning process would be important for accomplishing a learning objective through the mutual complementation of students' weaknesses. In response, Long (1983) emphasized the importance of group activities, saying that learning can be performed when learners concentrate on deducing understandable and meaningful outputs from inputs. 


\section{Flipped Learning}

Flipped learning, also called 'inverted instruction,' is different from the traditional instructor-centered method of giving a one-sided lecture. In the early spreading stage of the flipped learning, some people lacked understanding and perceived the flipped learning as "Learning at home and doing assignments at school". Then, FLN (2014) introduced 4 pillars for flipped learning and emphasized the 'connectivity' of learning. It is a studentcentered educational method that allows learners to become the main leaders and actively engage in class lessons and asks instructors to play a supporting role as facilitators ( $\mathrm{Yu}$, 2015). Large, Platter and Treglia (2013) stated that flipped learning transforms traditional activities in the classroom into ones outside the classroom. In contrast to the traditional teaching method characterized by teaching in class and performing reviews and tasks outside the classroom, flipped learning involves differentiated preliminary learning outside the classroom followed by advanced, supplementary learning with instructors and classmates in the classroom (Johnson \& Renner, 2012). Accordingly, a class utilizing flipped learning enables advanced learning in the classroom owing to preliminary basic learning (Gang, Park, Park, \& Park, 2014).

Flipped learning is an education form similar to blended learning. However, flipped learning is different from blended learning as it provides online learning through advanced study and it connects online and offline learning organically for the instructional design. (Ahn, 2016; Kang, 2016; Kim, Kim, \& Kim, 2016).

Flipped learning has strength of allowing flexible learning at anytime and anywhere using ICT. Also, the students to get interested in learning in the environment accessible through mobile and tablet PC. To make students approach learning environment anytime and anywhere, the flipped learning also provides self-directed learning and self-regulated learning environment (Seo, 2017).

In the flipped learning, the preliminary learning helps the learner to carry out the process of understanding and memorizing the materials independently. Then, the learner analyzes, applies, integrates the concept through various in-class learning activities and make a creative result. Flipped learning is utilized as the ideal teaching and learning model in terms of affective feature, perception, and education as it leads the learner into the advanced thinking process (Heinerichs, Pazzaglia, \& Gilboy, 2016). Sung (2015) suggested that flipped learning and various in-class learning activities make students get interested in learning, synchronizing, and enhancing chance of interaction. Sung also stated that when the students participate in the class after the advanced study, the students can predict the learning material and it sharply reduces fear of English and helps the learner to express opinion confidently especially for EFL learner.

Although flipped learning has affective, definitional, and educational strengths, many 
researchers pointed out following issues involved in the flipped learning. Heinerichs et al. (2016) said that the instructor and the learner have the burden of preparing two different learning processes of 'advanced learning' and 'classroom learning. Also, the researchers suggested that organic connection between 'advanced learning' and 'classroom learning' would lead to accomplishment of ultimate learning goal and that such feature requires elaborate and organized teaching method design to the instructor. They also pointed out that the learner would feel uncomfortable in participating in the classroom learning when they are unprepared for the class. Also, for the instructor who are not familiar with ICT, the flipped learning might be burdensome (Kim et al., 2016).

Kang (2016) conducted a survey on instructors who applied the flipped learning in their class. The survey result showed that the instructors had the most difficulty in designing the in-class learning activity. Based on such result, Kang suggested that classroom activity is as significant as the online learning and that classroom activity may have influence on the success or failure of the flipped learning.

\section{RESEARCH METHODS}

\section{Research Participants}

A total of 42 undergraduate students at a private university located in Chungbuk, who had chosen Screen English as a Liberal Arts elective course participated in this study. They were freshman, sophomores, juniors and seniors majoring in various subjects, with various levels of English competency. Their TOEIC scores ranged from 310 to 830. In this research, the participants directly took part in plot presentations and discussion during class and completed a questionnaire survey on the educational method.

TABLE 1

Distribution of Research Participants Among Various Departments

\begin{tabular}{cccc}
\hline & & Frequency & $\%$ \\
\hline Academic & International Trade & 6 & $(14.3)$ \\
Department & Social Welfare & 8 & $(19.0)$ \\
& Flight Operation & 9 & $(21.4)$ \\
Food Technology & 3 & $(7.1)$ \\
Clinical Pathology & 5 & $(11.9)$ \\
Aerospace Material & 5 & $(11.9)$ \\
& Business Administration & 2 & $(4.8)$ \\
Aviation Maintenance & 1 & $(2.4)$ \\
Nursing & 1 & $(2.4)$ \\
Law & 2 & $(4.8)$ \\
Total & 42 & $(100.0)$ \\
\hline
\end{tabular}




\section{Assessment Tools}

The detailed methods used in this research for the empirical analysis of collected data are as follows: First, frequency analysis was carried out to find the general characteristics of the participants. Second, a $t$-test for verifying mean difference was carried out according to general characteristics. Third, a nonparametric test, which is a nonparametric technique, was utilized along with categorical data and the $\mathrm{Z}$ values of individual departments to find out differences between various groups. All the empirical analyses in this research were verified at the significance level of $p<.05$, using the SPSSWIN 21.0 program for statistical treatment.

\section{Research Procedures}

This research was based on a questionnaire survey involving a total of 55 students who took a screen English course that utilized flipped learning based on the movie Love Actually (Curtis, 2003). The survey was conducted after students completed the course, which was given for a total of 30 hours over a 15 -week period from March 2 to June 8 , 2018.

\section{Procedures of Flipped Learning Based on the Movie Love Actually}

\section{1) Preliminary Learning Before Class}

A total of 42 students were divided into groups of 3-4 students. Each group was assigned to summarize the plot of a unit of the movie Love Actually. The groups were then directed to give presentations on their plot summaries over a 13-week period, which did not include midterm and final examination days. The plot assignments are divided into small units for each group. For this purpose, the students watched the movie or read the corresponding script to understand their content, and then met together in their groups to prepare a plot summary before giving a presentation in class. At the meeting, decisions were made as to who would prepare a PowerPoint presentation (PPT) and who would deliver the presentation. All the members were to take part in preliminary learning by being involved in the presentation directly or indirectly.

To prepare a plot summary, the students had to watch the movie 3-4 times or concentrate on reading the corresponding script. Then, they wrote down its major elements such as character introduction, background description, story development, events, and overcoming difficulties, in several paragraphs according to the structure of introduction, development, turn and conclusion. Each paragraph had to consist of concrete sentences 
containing detailed information about the 'who, what, where, when, and how' of the story.

After the plot summary was prepared, the group leader sent their PPT file to the instructor by email and the instructor replied with feedback addressing any part of the file that needed improvement. Upon receiving the feedback, the students prepared a revised version and sent it back to the instructor by email. Finally, the instructor returned the file after format proofreading to the students by email.

Another group of students carefully prepared 7-10 discussion questions in English regarding the unit of the movie. After the questions were prepared, the group sent them to the instructor by email, and then received feedback regarding their content and format. Through such a series of preparative processes before class, students had an opportunity for preliminary learning and became confident about presenting their plot summaries and discussion questions.

\section{2) Activities in the Classroom}

In the classroom, the appropriate group presented their plot summary in English, using their PPT file, according to the details of their preliminary learning. After that, all the students watched the corresponding unit of the movie. Then, they studied the text of the unit together with the instructor. The textbook used was Love Actually (Curtis, 2006), published by Screen English The textbook consists of a total of 9 units. The screenplay is written in both English and Korean, which made it easier for students to understand. It also allowed detailed and advanced learning, with the instructors' help, about whatever they had overlooked while presenting the plot or watching the movie. Upon completing the text study, individual groups addressed the discussion questions prepared by a group from a different department.

TABLE 2

Methods of Screen English Class Utilizing Flipped Learning

\begin{tabular}{|c|c|c|}
\hline Procedures & Contents & Methods \\
\hline $\begin{array}{l}\text { Preliminary } \\
\text { Learning }\end{array}$ & $\begin{array}{l}\text { 1) Preliminary activity in order to } \\
\text { be prepared for presentation } \\
\text { 2) Preparation for presentation, by } \\
\text { groups, after watching a movie } \\
\text { or reading a corresponding } \\
\text { book } \\
\text { 3) Instructor's feedback and } \\
\text { suggestion }\end{array}$ & $\begin{array}{l}\text { Each group of 3-4 students watches a movie } \\
\text { assigned to their department, prepare a PPT } \\
\text { file by summarizing the plot and content, } \\
\text { send the file to the instructor by email, and } \\
\text { then receive feedback for revision. }\end{array}$ \\
\hline $\begin{array}{l}\text { Presentation of } \\
\text { Movie Plot by } \\
\text { Groups }\end{array}$ & $\begin{array}{l}\text { 4) PPT presentation with the } \\
\text { contents revised through } \\
\text { instructor's feedback }\end{array}$ & $\begin{array}{l}\text { A student selected randomly from the group } \\
\text { prepared for presentation makes a } \\
\text { presentation in English, using the PPT file } \\
\text { revised according to instructor's feedback. }\end{array}$ \\
\hline
\end{tabular}


Utilizing Flipped Learning in the English Language Classroom:

A Study on a Movie, Love Actually-Based Curriculum

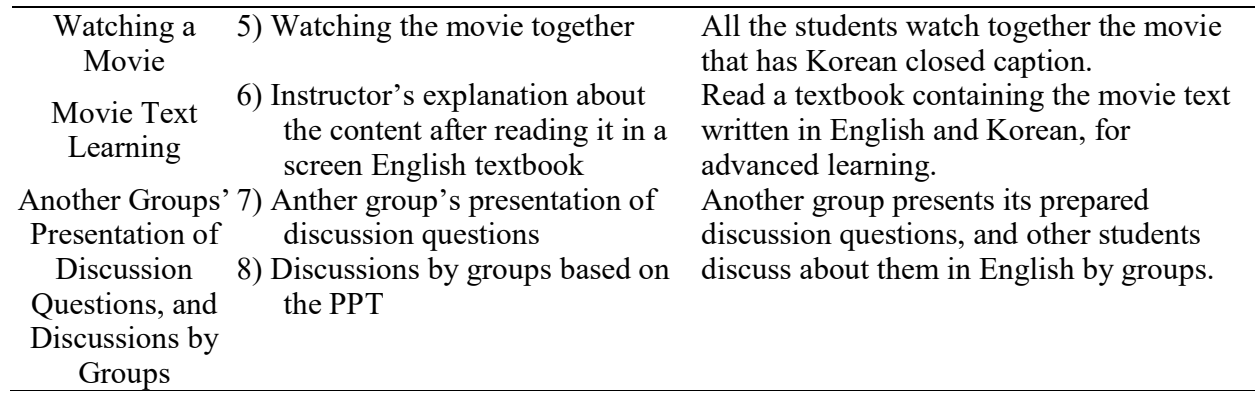

\section{RESEARCH RESULTS}

\section{Merits of a Movie-Based English Class Utilizing Flipped Learning}

TABLE 3

Merits of a Movie-Based English Class Utilizing Flipped Learning

\begin{tabular}{cccc}
\hline \hline & Frequency & $\%$ & $x^{2}(d f)$ \\
\hline Increased interest in English & 22 & 52.3 & $30.38^{* * *}$ \\
Listening ability improvement & 12 & 28.5 & $(3)$ \\
Presentation ability improvement & 2 & 4.9 & \\
$\begin{array}{c}\text { Critical thinking ability improvement after } \\
\text { movie-based class, owing to presentation }\end{array}$ & 6 & 14.3 & \\
TOTAL & 42 & 100.0 & \\
$* * * p<.001$ & &
\end{tabular}

The greatest merit of a movie-based class was shown to be 'increased interest in English' (52.3\%), followed by 'improved listening ability' $(28.5 \%)$ and 'improved critical thinking ability after completing a movie-based class, owing to presentations' $(14.3 \%)(p<.001)$. Thus, the merits of a movie-based English class utilizing flipped learning were 'increased interest in English,' 'improved listening ability,' 'improved critical-thinking,' and 'improved presentation ability.' These results were statistically significant.

\section{Weaknesses of a Movie-Based English Class Utilizing Flipped Learning}

TABLE 4

Weaknesses of a Movie-Based English Class Utilizing Flipped Learning

\begin{tabular}{cccc}
\hline \hline & Frequency & $\%$ & $x^{2}(d f)$ \\
\hline Fast speed & 7 & 16.7 & $15.71^{* *}$ \\
Listening difficult pronunciation & 4 & 9.5 & $(5)$ \\
\hline
\end{tabular}




\begin{tabular}{ccc}
\hline Vocabulary learning & 12 & 28.6 \\
Grammar learning & 13 & 31.0 \\
Cultural background learning & 5 & 11.9 \\
Others & 1 & 2.3 \\
\hline$* 0<01$ & &
\end{tabular}

As for opinions about a movie-based class, the greatest weakness of a movie-based English class was shown to be 'insufficient grammar learning' (31\%), followed by 'insufficient vocabulary learning' (28.6\%), 'fast speed' (16.7\%) and 'insufficient cultural background knowledge' $(11.9 \%)(p<.001)$. Thus, the weaknesses of a movie-based English class utilizing flipped learning were 'grammar learning,' 'vocabulary learning,' 'fast speed,' 'cultural background knowledge' and 'listening to difficult pronunciation.' These results were statistically significant.

\section{Opinions About Students Presenting Plot Summaries During a Movie-Based Class Utilizing Flipped Learning}

TABLE 5

Opinions About Students Presenting Plot Summaries During a Movie-Based Class Utilizing Flipped Learning

\begin{tabular}{cccc}
\hline \hline & Frequency & $\%$ & $x^{2}(d f)$ \\
\hline Positive & 34 & 81.0 & \multirow{2}{*}{$16.095^{* * *(1)}$} \\
\hline Negative & 8 & 19.0 & \\
\hline$* * * p<.001$ & & &
\end{tabular}

As for opinions about presenting movie plots after watching Love Actually, $81.0 \%$ of students showed a positive response, while $19.0 \%$ showed a negative response $(p<.001)$. These results were statistically significant, indicating that most of the students regarded the plot presentations positively.

\section{Opinions About Group Discussion During a Movie-Based Class Utilizing Flipped Learning}

TABLE 6

Opinions About Group Discussion During a Movie-Based Class Utilizing Flipped Learning

\begin{tabular}{rccc}
\hline \hline & Frequency & $\%$ & $x^{2}(d f)$ \\
\hline Positive & 33 & 78.6 & $13.714^{* * *(2)}$ \\
Negative & 9 & 21.4 & \\
\hline$* * * p<.001$ & & &
\end{tabular}


As for opinions about discussing movie content after watching Love Actually, 78.6 \% of students showed a positive response, while $21.4 \%$ showed a negative response ( $p$ $<.001)$. These results were statistically significant, indicating that most of the students regarded discussion about the movie content during class positively.

\section{Opinions by Gender About the Merits and Weaknesses of a Movie- Based Class Utilizing Flipped Learning}

TABLE 7

Differences Between Genders in Opinions About a Movie-Based English Class Utilizing Flipped Learning

\begin{tabular}{|c|c|c|c|c|c|c|}
\hline \multirow{4}{*}{$\begin{array}{l}\text { Weaknesses } \\
\text { of Movie- } \\
\text { based English } \\
\text { Class }\end{array}$} & \multirow[b]{3}{*}{ Fast speed } & \multicolumn{4}{|c|}{ Genders } & \multirow{3}{*}{$\begin{array}{c}\mathrm{x}^{2}(d f) \\
1.684(5)\end{array}$} \\
\hline & & \multicolumn{2}{|c|}{ Male \% } & \multicolumn{2}{|c|}{ Female \% } & \\
\hline & & 6 & 17.1 & 1 & 14.3 & \\
\hline & $\begin{array}{l}\text { Difficult pronunciation } \\
\text { phenomena }\end{array}$ & 4 & 11.4 & 0 & .0 & \\
\hline $\begin{array}{c}\text { Class } \\
\text { Utilizing }\end{array}$ & Insufficient vocabulary ability & 9 & 25.7 & 3 & 42.9 & \\
\hline \multirow[t]{3}{*}{$\begin{array}{l}\text { Flipped } \\
\text { Learning }\end{array}$} & $\begin{array}{l}\text { Insufficient grammar } \\
\text { knowledge }\end{array}$ & 11 & 31.4 & 2 & 28.6 & \\
\hline & $\begin{array}{c}\text { Insufficient cultural } \\
\text { background knowledge }\end{array}$ & 4 & 11.4 & 1 & 14.3 & \\
\hline & Others & 1 & 2.9 & 0 & .0 & \\
\hline \multirow{6}{*}{$\begin{array}{c}\text { Merits of } \\
\text { Movie-based } \\
\text { English Class } \\
\text { Utilizing } \\
\text { Flipped } \\
\text { Learning }\end{array}$} & Increased interest in English & 19 & 54.3 & 2 & 28.6 & $4.644(4)$ \\
\hline & Listening ability improvement & 7 & 20.0 & 4 & 57.1 & \\
\hline & $\begin{array}{l}\text { Vocabulary ability } \\
\text { improvement }\end{array}$ & 3 & 8.6 & 0 & .0 & \\
\hline & $\begin{array}{c}\text { Presentation ability } \\
\text { improvement }\end{array}$ & 1 & 2.9 & 0 & .0 & \\
\hline & $\begin{array}{c}\text { Thinking ability improvement } \\
\text { after movie-based class, owing } \\
\text { to presentation }\end{array}$ & 5 & 14.3 & 1 & 14.3 & \\
\hline & TOTAL & 35 & 100.0 & 7 & 100.0 & \\
\hline
\end{tabular}

As for opinions about a movie-based class by gender, the greatest weakness of a moviebased English class was shown to be 'insufficient grammar knowledge' (31.4\%) for male students, and 'insufficient vocabulary ability' (42.9\%) for female students. From this result it could be inferred that male students put more weight on, and feel more weakness in, grammar knowledge compared to female students; whereas female students put more weight on, and feel weakness in, vocabulary learning. The greatest merit of a movie-based English class was shown to be 'increased interest in English' (54.3\%) for male students, and 'listening ability improvement' $(57.1 \%)$ for female students. From this result it could 
be inferred that male students put more weight on interest when taking a movie-based English class, whereas female students put more weight on listening ability improvement. Such differences, however, were not significant at a significance level of $p<.05$. Thus, this result indicated that there was little difference between genders in opinions about a movie-based English class utilizing flipped learning.

\section{DISCUSSION}

The purpose of this research study is to understand the effects of a movie, Love Actuallybased curriculum utilizing flipped learning on English language learners. To attain this purpose, this study investigated the opinions of undergraduate students through a questionnaire-based survey. The discussions and interpretations of the research results are as follows.

Firstly, one of the greatest merits of the Love Actually-based English class utilizing flipped learning is that it induces an interest in English. This shows that learning English through a movie can create a strong motivation for learning. Moreover, repetitively appreciating a movie as part of preliminary learning can help improve listening skills naturally. The research results of the study imply that this learning method promotes natural content and learning environments in the similar way as when students learn their mother tongue, and helps learners develop an interest in learning and improve their listening skills.

Secondly, most participants responded that the biggest weakness of a movie-based English class utilizing flipped learning was learning grammar, and the second biggest weakness was improving vocabulary skills. These results suggest that a movie-based English class utilizing flipped learning cannot contribute significantly to learning vocabulary or grammar in depth, despite improving natural listening skills or increasing interest. Thus, it would be good to complement this method with online vocabulary or grammar learning programs during preliminary learning, which might help students, overcome such a problem.

Utilization of flipped learning's strengths at maximum, making up for the burdensome factors, seeking design and operation for teaching, learning model applied with the flipped learning which can be used in university level English class are necessary for overcoming the limitations of this study. Kang (2016) made learners to study vocabulary, study listening, and watch YouTube videos for advanced learning. Kang (2016) also carried out various in-class group activities focusing on communication. In the advanced learning for vocabulary and listening, the learners finished vocabulary and listening problem solving from the mobile application and the result was posted on the blackboard. 
Thirdly, it revealed positive student opinions about making plot presentations themselves during a movie-based English class utilizing flipped learning. Such a result indicates that learning processes conducted before class, for example, the activity of previewing the movie or creating plot presentations in groups, enhance students' sense of confidence presenting in English while giving them the satisfaction of learning.

Fourthly, it identified positive student opinions about group discussion during a moviebased English class utilizing flipped learning. This shows that learning processes with several stages, that is, watching a movie as preliminary learning, watching a movie once again during class, and learning relevant content, in depth, based on Korean and Englishstructured English text, provide an insightful understanding about the story of a movie creating confidence and positive thinking towards English discussion.

Lastly, it identified that there was little difference by gender, in the opinions of the merits and weaknesses of a movie-based English class utilizing flipped learning. However, concerning the merits of the class, there appeared diverse opinions between male and female students. In other words, male students responded that they had a greater interest in the class, while female students responded that the class helped them improve their listening skills.

As for the weaknesses of the class, male students pointed out that it was of little help for them to improve their knowledge about grammar, while female students felt that it did not help improve their vocabulary skills. It is revealed that although such differences were extremely intriguing, they were not statistically significant. Accordingly, it is suggested that instructors teach student with little regard for these gendered differences.

The research findings of the study show that a Love Actually-based English class utilizing flipped learning has fostered an interest in English learning in undergraduate students in the era of globalization. Two preliminary learning tools, plot presentations and discussion questions, seem instrumental for instructors to provide proper pedagogical teaching pedagogical methods and for students to actively engage in class. In that sense, this research is significant. However, such a learning method did not contribute to student satisfaction regarding improvements in vocabulary or grammar skills, as with more general English learning methods utilizing physical textbooks. Taking this into account, it is expected that complementing movie-based classes utilizing flipped learning with online or digital preliminary learning would result in a more satisfactory learning outcome.

This survey-based study has limits in identifying the practical learning effect of the flipped learning using the movie. Therefore, it is necessary for the follow-up studies to suggest the improved teaching and learning model for English class applied with the flipped learning based on the post-testing on the learners and survey result on perception toward the flipped learning. 


\section{REFERENCES}

Ahn, M. R. (2016). A study on influence and factors for satisfaction on flipped learning class using YouTube video. Journal of Multimedia Language Education, 19(1), 114-136.

Bueno, K. A. (2009). Got film? Is it a readily accessible window to the target language and culture for your students? Foreign Language Annals, 42(2), 318-339.

Choe, Y., \& You, M. (2003). English education via movies. STEM Journal, 4(1), 199-221.

Curtis, R. (Director/Writer). (2003). Love actually [Motion picture]. United State: Universal Pictures.

Curtis, R. (2006). Love actually (S. Woo, Trans.) Seoul: Screen English.

FLN. (2014). Definition of flipped learning. Retrieved from https://flippedlearning.org/definition-of-flipped-learning/

Galloway, B. (1992). A design for the improvement of the teaching of culture in foreign language classrooms. Yonkers, NY: American Council on the Teaching of Foreign Languages.

Gang, H. J., Park, S. P., Park, S. Y., \& Park, J. Y. (2014). The significance of flipped learning and exploratory study on educational environment. Journal of Digital Convergence, 12(9), 313-323.

Gardner, R., Lalonde, R., Moorcroft, R., \& Evers, R. (1987). Second language attrition: The role of motivation and use. Journal of Language and Social Psychology, 6(1), 173-180.

Hayati, A., \& Mohmedi, F. (2011). The effect of films with and without subtitles on listening comprehension of EFL learners. British Journal of Educational Technology, 42(1), 181-192.

Heinerichs, S., Pazzaglia, G., \& Gilboy, M. B. (2016). Using flipped classroom components in blended courses to maximize student learning. Athletic Training Education Journal, 11(1), 54-57.

Johnson, L., \& Renner, J. (2012). Effect of the flipped classroom model on a secondary computer applications course: Student and teacher perceptions, questions and student achievement (Doctoral Dissertation, University of Louisville, 2013), Dissertation Abstracts International, 54, 43B.

Kang, N. H. (2016). A study on suggestion of English lecture model applied with flipped learning, The Korean society of culture and convergence. In L. Yong (Ed.) The Korean Society of Culture and Convergence Summer National Academic Conference Material (pp. 405-415). Chungbuk: The Korean Society of Culture and Convergence.

Kim, D. W., Kim, B. S., \& Kim, J. H. (2016). A study on development of newly appointed instructor's expertise based on cases of flipped classroom. Journal of Elementary 
Education, 29(4), 1-23.

Kimbell, T. (2018). An overview: American television series as authentic resources for English language development. STEM Journal, 19(2), 1-19.

Koh, S. (2013). The impact of captions and subtitles in film on the listening comprehension and oral communication of EFL students. STEM Journal, 14(1), 17-36.

Krashen, S. D. (1982). Principles and practices in second language acquisition. Oxford: Pergamon Press.

Large, M., Platt, G., \& Treglia, M. (2013). Inverting the classroom: Gateway to creating an inclusive learning environment. Journal of Economic Education, 31(1), 30-43.

Lee, Y. J., \& Lee, J. (2012). Why movies? Revisiting the policy of supporting general English education: Using Good Will Hunting. STEM Journal, 13(3), 89-103.

Lewis, M. (2000). There is nothing as practical as a good theory. In M. Lewis (Ed.), Teaching collocation: Further development in the lexical approach (pp. 10-27). London: Language Teaching.

Lim, J. H. (2010). Class utilizing digital textbooks in elementary schools: Issues and tasks. Educational Practice Research, 9(1), 87-114.

Long, M. R. (1983). Native speaker/non-native speaker conversation and the negotiation of comprehensible input. Applied Linguistics, 4(2), 126-141.

Mayer, R. E. (2002). Cognitive theory and the design of multimedia instruction: An example of the two-way street between cognition and instruction. New Directions for Teaching and Learning, 89(1), 55-71.

Pak, H. H. (2013). The effect of films with and without subtitles on vocabulary acquisition scores of foreign language learners: Using a Korean sit-com, unhindered high-kick. STEM Journal, 13(3), 23-31.

Park, H. A. (2008). A study on the real status of utilizing elementary digital English textbooks. Contemporary English Lesson, 9(3), 123-151.

Roell, C. (2010). Intercultural training with films. English Teaching Forum, 2, 2-15.

Schmidt, R. (1990). The role of consciousness in second language learning. Applied Linguistics, 11(2), 137-140.

Seo, J. M. (2017, July). Effective operation of practical courses using flipped learning and smart devices: A case study on course for writing business English document. Paper presented at the 2017 Summer Conference of the Korean Society of Culture and Convergence, Seoul, Korea.

Stempleski, S. (2000). Video in the ESL classroom: Making the most of movies. ESL Magazine, 3(2), 10-12.

Son, M., \& Kim, S. Y. (2013). The effects of using a digital textbook on problem-solving and learning satisfaction in social studies. Korea Elementary Education, 24(4), 111- 
125.

Sung, K. (2015). A case study on a flipped classroom in an EFL content course. Multimedia Assisted Language Learning, 18(2), 159-187.

Vygotsky, L. S. (1978). Interaction between learning and development. In M. Cole, V. John-Steiner, S. Scribner, \& E. Souberman (Eds.), Mind in society: The development of higher psychological processes (pp. 79-91). Cambridge, MA: Harvard University Press.

Yoon, S. D., \& Ahn, D. K. (2012). The effect of film with or without subtitles on leaners' vocabulary enhancement in Korea: Using subtitles from Aladdin, The little mermaid, and The lion king. STEM Journal, 13(3), 73-87.

Yu, S. M. (2015). Re-searching for learning values viewed from the fever of flipped learning, and the roles of EBS. Media and Education, 5(1), 14-36.

\section{APPENDIX}

A sample of plot ppt for presentation

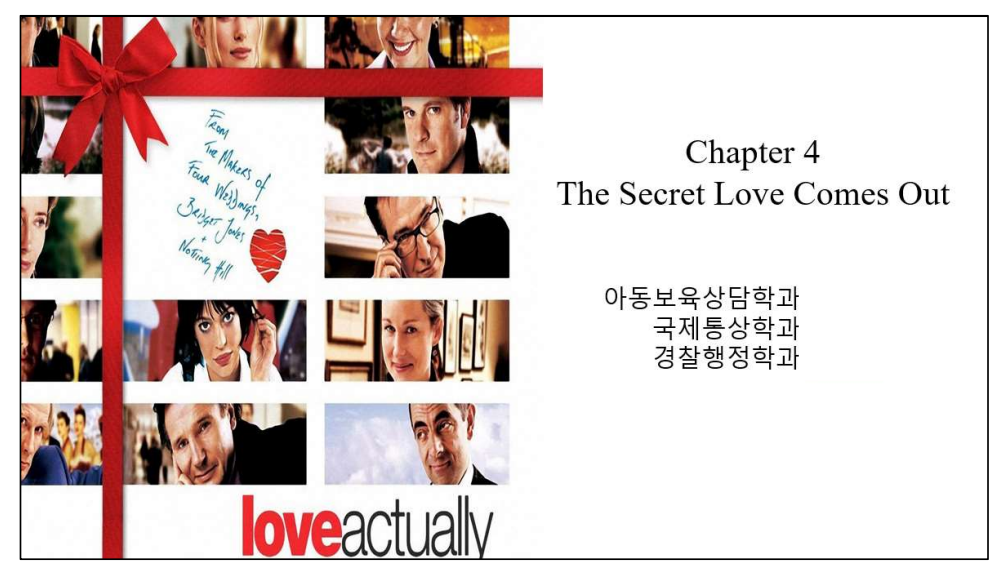


Utilizing Flipped Learning in the English Language Classroom: A Study on a Movie, Love Actually-Based Curriculum

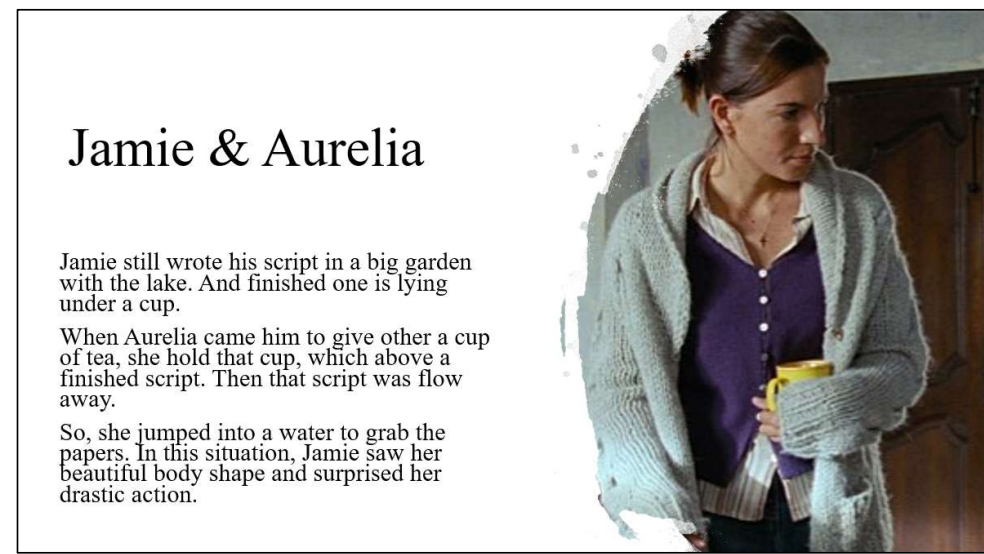

\section{Mark \& Juliet}

Juliet thought that Mark didn't like her very much. Juliet wanted to find her wedding video, so she came to Mark's house.

However, he didn't wanted to show her the video

which concluded every part focused on Juliet.

Eventually, Juliet found a video and played, and she was surprised at that time because it was filled with only her scenes.
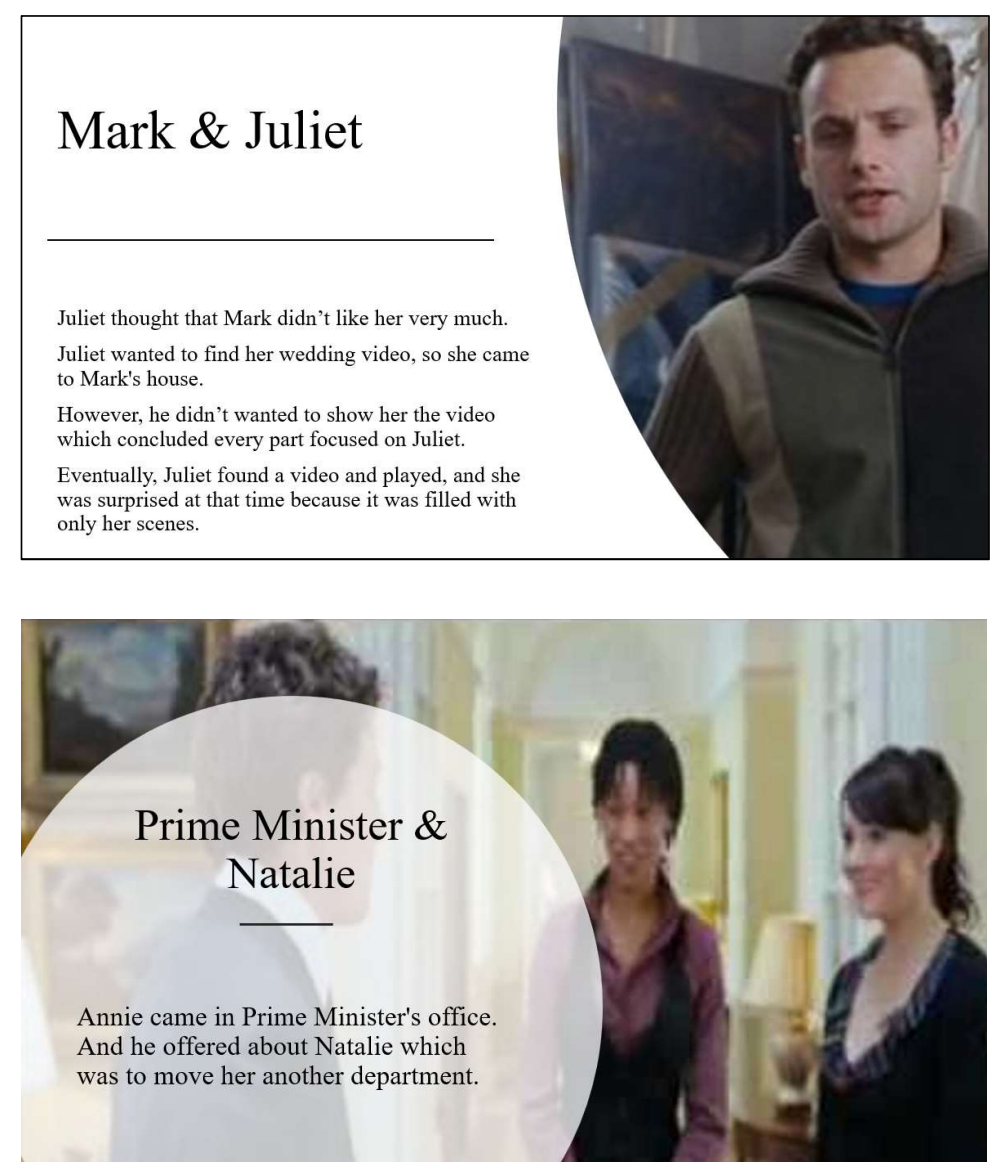
Applicable level: college

Keywords: flipped learning, EFL, study on a movie, a movie-based curriculum, Love actually, college students

Lim, Juyoung

Department of Global Language Liberal Art, Jungwon University

85 Munmuro, Geosanup, Geosangun,

Chungchungbukdo, 28024, Korea

E-mail: lisaim@jwu.ac.kr

Received: September 23, 2018

Revised version: November 13, 2018

Accepted: November 25, 2018 